\title{
Factors Associated with Changes in Body Mass Trajectories during Infancy: A Longitudinal Analysis in Japan
}

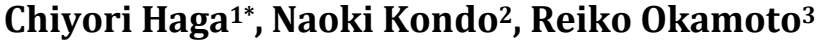 \\ ${ }^{1}$ Health Sciences Department, The University of Okayama, Okayama, Japan \\ ${ }^{2}$ School of Public Health, The University of Tokyo, Tokyo, Japan \\ ${ }^{3}$ Division of Health Sciences, Osaka University Graduate School of Medicine, Osaka, Japan \\ Email: *chiyori@okayama-u.ac.jp
}

How to cite this paper: Haga, C., Kondo, N. and Okamoto, R. (2016) Factors Associated with Changes in Body Mass Trajectories during Infancy: A Longitudinal Analysis in Japan. Health, 8, 1506-1517. http://dx.doi.org/10.4236/health.2016.814149

Received: October 3, 2016

Accepted: November 13, 2016

Published: November 16, 2016

Copyright $\odot 2016$ by authors and Scientific Research Publishing Inc. This work is licensed under the Creative Commons Attribution International License (CC BY 4.0).

http://creativecommons.org/licenses/by/4.0/ (c) (i) Open Access

\begin{abstract}
Maternal behaviour and child birth outcomes have been shown to be associated with the risk of disease in children. However, little is known about their association with the trajectories of physical development. The aim of this study was to identify factors associated with body mass index (BMI) trajectories in Japanese toddlers. All 900 children born in Ibara City between 2006 and 2009 were enrolled in this study with their mothers. Children's heights and weights were measured, as was BMI (weight $[\mathrm{kg}] /$ height $[\mathrm{m}]^{2}$ ). Multilevel analyses examined the association of maternal behaviour (smoking, using formula milk, and leaving the child in a daytime nursery) and birth outcomes (weight, parity, and gestational age) with standardized BMI trajectories (z-score analysis). Average BMIs \pm standard deviations at birth and at $1.5,2$, and 3 years were $12.6 \pm 1.3,16.8 \pm 1.2,16.1 \pm 1.2$, and $15.7 \pm 0.1$, respectively. Maternal behaviour was not associated with BMI trajectories. However, BMIs of low birth weight children at 3 years were significantly higher than those of other children $(\beta=$ $1.799, P<0.001)$, although the increments slightly decreased over time $(\beta=-0.035$, $P<0.001)$. The BMI increments of prematurely born children also slightly decreased over time $(\beta=-0.04271, P<0.001)$. Other evaluated factors were not associated with BMI trajectories. Our results showed that low birth weight children are more likely to exhibit lower BMIs until 2 years of age; however, BMI rapidly rises afterwards. Longer follow-up periods are warranted to evaluate the consequence of the late-year rapid increases in BMI among low birth weight children.
\end{abstract}

\section{Keywords}

Body Mass Trajectory, Infant Weight, Child Health, Obesity 


\section{Introduction}

Environmental influences in utero and in early infancy, especially maternal diet and smoking, are associated with several diseases later in a child's life; these include metabolic syndrome, coronary heart disease, and type 2 diabetes [1] [2] [3] [4]. To prevent these afflictions, it is important to control body size from as early in infancy as possible.

Growth during the first year of life involves a rapid increase in body mass index (BMI). BMI subsequently declines and reaches its nadir at around 6 years of age, and then resumes increasing. This second rise in the BMI curve is referred to as the adiposity rebound (AR). Many studies found that the timing of the AR may be predictive of obesity in adulthood [5]-[10]. Some studies also revealed an association between weight gain during infancy and obesity later in life [11] [12]. However, studies that examined individual BMI trajectories concluded that an early AR was not associated with being overweight in early life [13], and that increments of weight gain in early infancy were not associated with the timing of AR [14]. These results collectively imply that more studies are required to clarify the relationship between body mass trajectories in childhood and long-term health.

To our knowledge, only the duration of breast feeding [15] and maternal smoking during pregnancy [16] have been investigated for their influences on growth patterns during infancy; no studies have examined the role of broader maternal lifestyle habits during gestation and early infancy on obesity and thinness; such habits include working outside the home and enrolling children in daytime nurseries. Hence, the aim of this study was to identify infants' physical characteristics, as well as maternal behavioural factors that are associated with BMI trajectories in Japanese toddlers from birth until the age of 3 years.

\section{Patients and Methods}

\subsection{Study Cohort}

The study was performed in Ibara, a rural city that had a population of 41,713 in September 2016; one-half of the populace works in primary or secondary industries, and the remainder works in the tertiary industry sector. The city is located in Okayama Prefecture, and its residents include a high proportion of elderly individuals who are 65 years or older (42.0\%); the fertility rate in Ibara was $0.6 \%$ in 2011 . All children born in this city receive infant health checks at a health centre during their preschool years; their data are stored at a regional health centre. We conducted a retrospective analysis of data from all 900 children (469 boys and 431 girls) born in Ibara between April 2, 2006 and March 31, 2009, as well as data from their mothers. A questionnaire-based survey of maternal lifestyle during pregnancy was conducted to determine any associations with BMI changes at the time of each visit.

This study was approved by the Research Ethics Committee of the Graduate School of Health Science at the University of Okayama(approval number T14-01), and was conducted in accordance with the Guidelines Concerning Epidemiological Research (Ministry of Education, Culture, Sports, Science, and Technology; and Ministry of Health, 
Labour, and Welfare; Japan), with the cooperation of the Ibara City Municipality. Individual informed consent was not required for this retrospective study; however, parents and other citizens were informed of the potential utilization of health check-up data for research purposes via public notices posted on information boards at the community health centres in the city.

\subsection{Data Collection}

Standard anthropometric measurements of children's lengths/heights and weights using strict protocols were conducted by a small group of trained staff at 1.5, 2, and 3 years of age. In Japan, regular health check-ups for children of these age groups, especially 1.5 -and 3 -year olds, are legally required to be performed by the municipal government. Length or height was measured to the nearest $0.1 \mathrm{~cm}$ using a baby digital table at birth and at follow-up sessions before the age of 1 year; a digital height and weight scale was used thereafter. Weight was assessed to the nearest $100 \mathrm{~g}$ using the digital weight scale. At each follow-up session, BMI was calculated from the measured height and weight using the formula: weight $(\mathrm{kg}) / \mathrm{height}(\mathrm{m})^{2}$. In children under 2 years of age, weight $(\mathrm{kg}) /$ length $(\mathrm{m})^{2}$ was used as a proxy for BMI. To maximize comparability, individual BMI z-scores were also calculated according to the World Health Organization Standards [17].

Reference data regarding birth length and weight, birth order, and gestational week of delivery were obtained from the Maternal and Child Health Handbook, an official publication containing guidelines for obstetric professionals and pregnant women as well as actual children's data.

Information on the following factors was collected and scored through interviews conducted by public health nurses during the children's regular health check-ups, and were considered independent environmental variables having a potential impact on BMI changes in children: maternal smoking habits ( $1=$ smoking or $0=$ non-smoking), enrolment in a daytime nursery ( $1=$ using or $2=$ not using), and using formula until 4 months of age $(1=$ using or $0=$ not using). Additionally, we incorporated age $(1=2$ years of age or older; $0=$ younger than 2 years) because the trajectory of BMI during infancy tends to change at the 2-year point.

\subsection{Statistical Analyses}

Data for the 900 children encompassed a maximum of 4 follow-up exams; BMI data were available for at least 1 of the 4 points of measure for 863 of our subjects. We focused on birth weight $(\mathrm{kg})$ and BMI $\left(\mathrm{kg} / \mathrm{m}^{2}\right)$, and excluded individuals for whom data on weight, height, age, or sex were unavailable. We used a 2-level random intercept models as follows: The time of measurement was set to levell and the individuals were set to level2. For level1, we specified the times of BMI measurements (at 1.5 years, 2 years, or 3 years) as ordinal. For level 2, we used the fixed effects of the infants' sex, gestational age, parity, maternal smoking, and attendance of a daytime nursery. The analyses were conducted with the statistical software SAS 9.3 (SAS Institute Inc., Cary, 
NC, USA) using the MIXED procedure for multilevel analyses with maximum likelihood estimation. To evaluate the association between level 2 predictor variables and the BMI trajectory, we modelled these individual variables and interaction terms for each individual variable as well as the time variable.

\section{Results}

\subsection{Characteristics of Participants}

Table 1 shows the distributions of the key variables. Over one-half of the participants were boys (51.8\%). There was no difference in maternal BMI for women giving birth to boys vs. girls. More boys were born pre-term than girls; however, more girls were born post-term than boys. No other variables differed significantly between the sexes. Additionally, there were 7 pairs of twins (14 children).

Table 2 shows the distributions of BMIs at each time point. The mean BMI \pm standard deviation of all children at birth was $12.6 \pm 1.3$, rising to $16.8 \pm 1.2$ at 1.5 years of age and decreasing to $15.7 \pm 1.2$ by the age of 3 years. There was no difference in the slope of this trajectory between boys and girls. Hence, the BMI increased after birth and attained its maximum at 1.5 years of age. It then decreased by 3 years of age in both sexes; the rate of decrease was higher in boys.

\subsection{Body Mass Trajectories during Infancy}

Regression coefficients associated with BMI effects during infancy are shown in Supplemental (Table 1). As might be expected, the BMI values estimated at each measurement points increased significantly in almost all models. However, the BMI change increments varied for each duration (1.5, 2, and 3 years of age); the largest increment was during the first period, after which it decreased gradually in all models.

When BMI at 3 years of age was estimated using a univariable model (Model 2), BMIs of low birth weight children were significantly lower than those of children without low birth weights $(\beta=-2.0189, P<0.001)$. BMI trajectories increased until 1.5 years of age, and then decreased in both categories of children; however, the differences in BMI decreased over time (Figure 1). As for BMI changes by gestational age, the BMI increments of prematurely born children were generally the same as for other children, and slightly decreased over time after the age of 1.5 years, as estimated by the crude model (Model 3) (Figure 2).

Similarly, we ran crude models focusing on factors closely related to birth weight (Models 4 - 8), but did not find statistically significant associations (Table S1). Parity and sex showed marginal associations; the BMIs of first-born children at 3 years of age were lower than those of their siblings; however, there were no significant differences with respect to age. Therefore, we ran adjusted models based on factors associated with parity and sex (Model 9).

\section{Discussion}

Our study investigated BMI trajectories and the factors associated with BMI changes in 
Table 1. Characteristics of study participants.

\begin{tabular}{|c|c|c|c|}
\hline \multirow{2}{*}{ Variable } & All & Boys & Girls \\
\hline & \multicolumn{3}{|c|}{ Mean \pm SD } \\
\hline \multicolumn{4}{|l|}{ BMI at birth } \\
\hline BMI & $12.63 \pm 1.25$ & $12.62 \pm 1.22$ & $12.66 \pm 1.29$ \\
\hline \multicolumn{4}{|l|}{ BMI at 3 years old } \\
\hline BMI & $15.69 \pm 1.15$ & $15.78 \pm 1.18$ & $15.60 \pm 1.11$ \\
\hline BMI z-score* & $0.10 \pm 0.87$ & $0.10 \pm 0.91$ & $0.11 \pm 0.82$ \\
\hline \multicolumn{4}{|c|}{ Level 2: Individual: $\mathrm{n}=899$} \\
\hline \multicolumn{4}{|l|}{ Year of birth } \\
\hline 2006 & $68(7.6 \%)$ & $38(8.2 \%)$ & $30(6.9 \%)$ \\
\hline 2007 & $292(32.5 \%)$ & $154(33.1 \%)$ & $138(31.9 \%)$ \\
\hline 2008 & $317(35.3 \%)$ & $149(32.0 \%)$ & $168(38.8 \%)$ \\
\hline 2009 & $222(24.7 \%)$ & $125(26.8 \%)$ & $97(22.4 \%)$ \\
\hline \multicolumn{4}{|l|}{ Sex } \\
\hline Male & \multicolumn{2}{|c|}{$466(51.8 \%)$} & \\
\hline Female & \multicolumn{2}{|c|}{$433(48.2 \%)$} & \\
\hline \multicolumn{4}{|c|}{ Maternal pre-pregnancy BMI } \\
\hline & $20.83 \pm 3.22$ & $20.78 \pm 3.16$ & $20.89 \pm 3.29$ \\
\hline \multicolumn{4}{|l|}{ Gestational age } \\
\hline Full term & $786(94.2 \%)$ & $406(92.9 \%)$ & $380(95.7 \%)$ \\
\hline Pre-term & $41(4.9 \%)$ & $29(6.6 \%)$ & $12(3.0 \%)$ \\
\hline Post term & $7(0.8 \%)$ & $2(0.5 \%)$ & $5(1.3 \%)$ \\
\hline \multicolumn{4}{|l|}{ Mother employed } \\
\hline No & $315(43.6 \%)$ & $165(43.0 \%)$ & $150(44.3 \%)$ \\
\hline Yes & $402(55.6 \%)$ & $216(56.3 \%)$ & $186(54.9 \%)$ \\
\hline Other & $6(0.8 \%)$ & $3(0.8 \%)$ & $3(0.9 \%)$ \\
\hline Birth weight & $3.05 \pm 0.44$ & $3.06 \pm 0.45$ & $3.04 \pm 0.43$ \\
\hline Low birth weight & $73(9.0 \%)$ & $38(8.4 \%)$ & $35(8.5 \%)$ \\
\hline \multicolumn{4}{|l|}{ Parity } \\
\hline First child & $288(40.3 \%)$ & $149(39.4 \%)$ & $139(41.3 \%)$ \\
\hline Others & $427(59.7 \%)$ & $229(60.6 \%)$ & $198(58.7 \%)$ \\
\hline \multicolumn{4}{|l|}{ Twin } \\
\hline Yes & 14 (7 pairs) $(1.6 \%)$ & 12 (6 pairs) $(2.6 \%)$ & $2(1$ pair) $(0.5 \%)$ \\
\hline \multicolumn{4}{|l|}{ Family Structures } \\
\hline Nuclear family & $471(67.4 \%)$ & $254(68.1 \%)$ & $217(66.6 \%)$ \\
\hline Extended family & $212(30.3 \%)$ & $116(31.1 \%)$ & $96(29.5 \%)$ \\
\hline Single parent family & $16(2.3 \%)$ & $3(0.8 \%)$ & $13(4.0 \%)$ \\
\hline \multicolumn{4}{|l|}{ Maternal smoking } \\
\hline Yes & $39(5.6 \%)$ & $20(5.4 \%)$ & $19(5.7 \%)$ \\
\hline \multicolumn{4}{|c|}{ Enrolment in a nursery at 4 months of age } \\
\hline Yes & $29(4.0 \%)$ & $14(3.7 \%)$ & $15(4.4 \%)$ \\
\hline \multicolumn{4}{|c|}{ Feeding behaviour until 4 months } \\
\hline Breast milk & $327(45.0 \%)$ & $167(43.6 \%)$ & $160(46.5 \%)$ \\
\hline Formula & $109(15.0 \%)$ & $52(13.6 \%)$ & $57(16.6 \%)$ \\
\hline Both & $291(40.0 \%)$ & $164(42.8 \%)$ & $127(36.9 \%)$ \\
\hline
\end{tabular}

${ }^{\star}$ BMI z-score at birth was not calculable, as it has no reference value. BMI: body mass index, SD: standard deviation. 


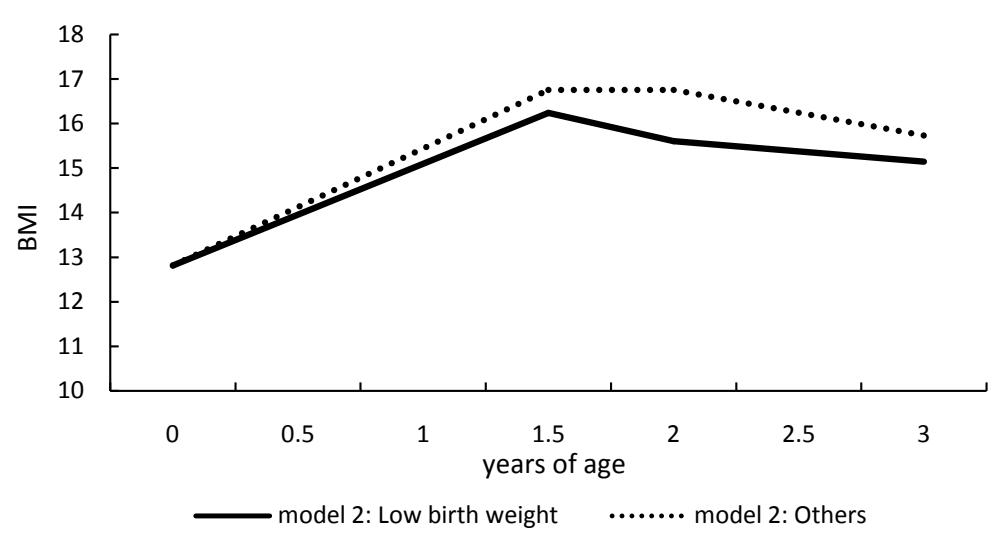

Figure 1. Predicted trajectories of body mass index by birth weight. The predicted values were adjusted for age and birth weight using multivariate linear regression.

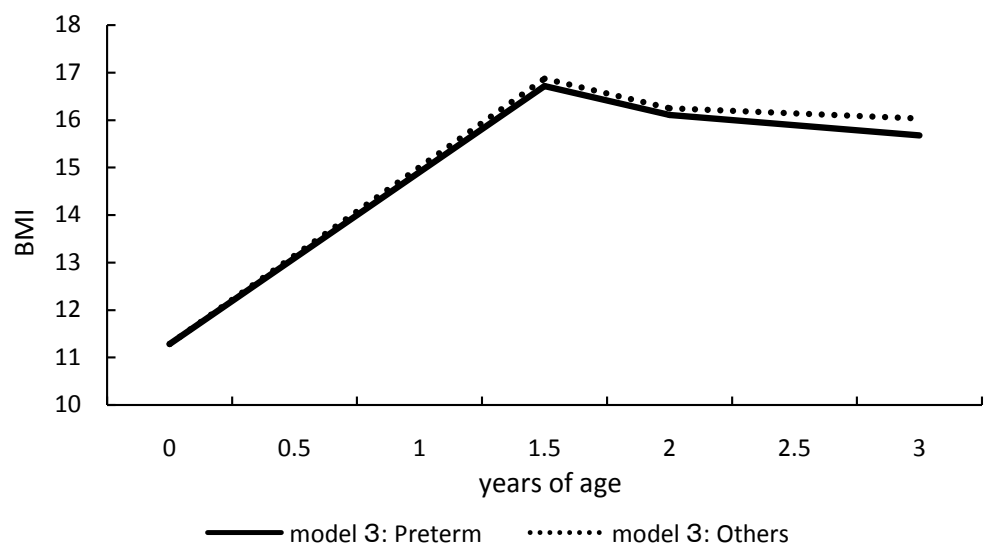

Figure 2. Predicted trajectories of body mass index by gestational age. The predicted values were adjusted for age and gestational age using multivariate linear regression.

Table 2. The number of participants, BMI ranges, and BMI z-scores.

\begin{tabular}{ccccc}
\hline \multirow{2}{*}{ Age at the point of measurement } & $\mathrm{n}$ & All & Boys & Girls \\
\cline { 2 - 5 } Birth & 863 & \multicolumn{3}{c}{ Mean \pm SD } \\
BMI & & $12.63 \pm 1.25$ & $12.62 \pm 1.22$ & $12.66 \pm 1.29$ \\
& & & & \\
1.5 years of age & 781 & & $16.96 \pm 1.27$ & $16.52 \pm 1.10$ \\
BMI & & $0.61 \pm 0.84$ & $0.64 \pm 0.91$ & $0.58 \pm 0.75$ \\
BMI z-score & 802 & & & \\
2 years of age & & $16.10 \pm 1.15$ & $16.19 \pm 1.22$ & $16.01 \pm 1.06$ \\
BMI & & $0.35 \pm 0.85$ & $0.31 \pm 0.92$ & $0.41 \pm 0.76$ \\
BMI z-score & 427 & & & \\
3 years of age & & $15.69 \pm 1.15$ & $15.78 \pm 1.18$ & $15.60 \pm 1.11$ \\
BMI & & $0.10 \pm 0.87$ & $0.10 \pm 0.91$ & $0.11 \pm 0.82$ \\
BMI z-score & & & & \\
\hline
\end{tabular}

BMI: body mass index, SD: standard deviation. 
Japanese infants born in a rural area. We found that the BMIs of low birth weight children tend to increase more slowly in the first 1.5 years of life, and to decrease more rapidly afterwards, when compared to non-low birth weight infants. Additionally, the rate of BMI increase in children of pre-term birth tends to be lower than that of other children. On the other hand, low birth weight is the only factor associated with BMI during infancy; maternal behaviour does not appear to be associated with BMI changes.

Our observations indicated that $\mathrm{AR}$ in children born prematurely and/or in those with low birth weights is achieved sooner than in other children. These results are consistent with those of previous studies [18] [19] [20]. Moreover, similar studies found that the timing of AR is predictive of obesity in adulthood [6] [13] [21], and low birth weight may also be associated with later childhood obesity [22] [23]. These data therefore suggest that children with low birth weights are at a greater risk of obesity compared to other children. However, when we investigated whether gestational age is associated with birth weight, we found that the rate of BMI change of children born prematurely did not increase any faster than that of other children after 2 years of age. Of note, BMIs of children not born prematurely might have been overestimated in our study, because our "not premature" subjects included children born post-term.

On the other hand, factors that other studies found to be associated with childhood obesity were not identified as such in our study. These factors included parity [19], maternal smoking during pregnancy [22] [24] [25] [26], feeding behaviour and period of breastfeeding [22] [27] [28], and enrolment in a daytime nursery (which was associated with the breastfeeding period). Our study only collected data of participants up to the age of 3 years, an age group in which the onset of obesity is very rare; therefore, we could not identify any associations with the actual onset of obesity. The collection of data between the ages of 3 years and adolescence (when obesity develops) is required to investigate the relationships between childhood obesity and each of the environmental factors described herein.

This study has some limitations. First, errors in measurement are likely, especially with respect to height. However, such errors were random; therefore, there ought to be no bias towards any particular classification. However, measurement errors can lead to the underestimation of associations between predictors and BMI trajectories; this may explain why most associations we tested were negative. Second, our data concerning feeding behaviour, enrolment in a daytime nursery, and smoking status were based on self-reporting questionnaires. Third, our follow-up period was too short to evaluate the risks associated with low birth weight; we are planning to conduct a study with a longer follow-up period in the future.

However, this study has several strengths. First, it was population-based and included a relatively large sample size. The subjects of this study were representative, as we used data from an entire population of children born in the city during a specific period. Second, this type of study investigating associations between life factors during infancy and the body mass trajectory, as determined using data collection 4 times in the first 3 years of life, is rare. Despite the previously mentioned limitations, our results in- 
dicate that $\mathrm{AR}$ in low birth weight children may appear during early infancy, a period much earlier than that observed for normal birth weight children. Our data also implies that low birth weight children may have a tendency towards obesity later in life owing to predisposition caused by an earlier AR.

\section{Conclusion}

Our data showed that low birth weight children showed greater decreases in BMI before attaining 2 years of age compared to non-low birth weight children, and also exhibited more rapid BMI increases after that age. However, maternal behaviour was not associated with BMI changes during infancy. This suggests that AR in low birth weight children may appear during early infancy. Factors associated with the rate of BMI decline before 3 years of age may be associated with obesity. However, our results do not prove that low birth weight is the only factor associated with obesity. Future studies to identify the effects of lifestyle factors on body mass trajectory that collect further longitudinal data, including the period of adolescence, are required.

\section{Acknowledgements}

The authors thank the staff of the Municipality of Ibara City for their cooperation.

\section{Funding}

This work was supported by a Grants-in-Aid for Scientific Research awarded by the Japan Society for the Promotion of Science (Grant Number JP2479254404).

\section{Declaration of Conflicting Interests}

The authors declare that they have no conflicts of interest.

\section{References}

[1] Barker, D.J.P., Osmond, C., Forsén, T.J., et al. (2005) Trajectories of Growth among Children Who Have Coronary Events as Adults. The New England Journal of Medicine, 353, 1802-1809. http://dx.doi.org/10.1056/NEJMoa044160

[2] Andersen, L.G., Ängquist, L., Eriksson, J.G., et al. (2010) Birth Weight, Childhood Body Mass Index and Risk of Coronary Heart Disease in Adults: Combined Historical Cohort Studies. PloS ONE, 5, e14126. http://dx.doi.org/10.1371/journal.pone.0014126

[3] Eriksson, J.G. (2011) Early Growth and Coronary Heart Disease and Type 2 Diabetes: Findings from the Helsinki Birth Cohort Study (HBCS). The American Journal of Clinical Nutrition, 94, 1799S-1802S. http://dx.doi.org/10.3945/ajcn.110.000638

[4] Salonen, M.K., Kajantie, E., Osmond, C., et al. (2009) Role of Childhood Growth on the Risk of Metabolic Syndrome in Obese Men and Women. Diabetes \& Metabolism, 35, 94100. http://dx.doi.org/10.1016/j.diabet.2008.08.008

[5] Rolland-Cachera, M.F., Deheeger, M., Bellisle, F., et al. (1984) Adiposity Rebound in Children: A Simple Indicator for Predicting Obesity. The American Journal of Clinical Nutrition, 39, 129-135.

[6] Whitaker, R.C., Pepe, M.S., Wright, J.A., et al. (1998) Early Adiposity Rebound and the Risk 
of Adult Obesity. Pediatrics, 101, E5. http://dx.doi.org/10.1542/peds.101.3.e5

[7] Taylor, R.W., Grant, A.M., Goulding, A., et al. (2005) Early Adiposity Rebound: Review of Papers Linking This to Subsequent Obesity in Children and Adults. Current Opinion in Clinical Nutrition \& Metabolic Care, 8, 607-612. http://dx.doi.org/10.1097/01.mco.0000168391.60884.93

[8] Williams, S.M. and Goulding, A. (2009) Early Adiposity Rebound Is an Important Predictor of Later Obesity. Obesity (Silver Spring), 17, 1310. http://dx.doi.org/10.1038/oby.2009.104

[9] Wong, S.C., Ng, S.M. and Didi, M. (2004) Children with Congenital Hypothyroidism Are at Risk of Adult Obesity Due to Early Adiposity Rebound. Clinical Endocrinology, 61, 441446. http://dx.doi.org/10.1111/j.1365-2265.2004.02116.x

[10] González, L., Corvalán, C., Pereira, A., et al. (2014) Early Adiposity Rebound Is Associated with Metabolic Risk in 7-Year-Old Children. International Journal of Obesity, 38, 12991304. http://dx.doi.org/10.1038/ijo.2014.97

[11] Andersen, L.G., Holst, C., Michaelsen, K.F., et al. (2012) Weight and Weight Gain during Early Infancy Predict Childhood Obesity: A Case-Cohort Study. International Journal of Obesity, 36, 1306-1311. http://dx.doi.org/10.1038/ijo.2012.134

[12] Baird, J., Fisher, D., Lucas, P., et al. (2005) Being Big or Growing Fast: Systematic Review of Size and Growth in Infancy and Later Obesity. BMJ, 331, 929. http://dx.doi.org/10.1136/bmj.38586.411273.E0

[13] Williams, S.M. and Goulding, A. (2009) Patterns of Growth Associated with the Timing of Adiposity Rebound. Obesity (Silver Spring), 17, 335-341.

http://dx.doi.org/10.1038/oby.2008.547

[14] Koyama, S., Sairenchi, T., Shimura, N., et al. (2015) Association between Timing of Adiposity Rebound and Body Weight Gain during Infancy. The Journal of Pediatrics, 166, 309312. http://dx.doi.org/10.1016/j.jpeds.2014.10.003

[15] Jensen, S.M., Ritz, C., Ejlerskov, K.T., et al. (2015) Infant BMI Peak, Breastfeeding, and Body Composition at Age 3 y. The American Journal of Clinical Nutrition, 101, 319-325. http://dx.doi.org/10.3945/ajcn.114.092957

[16] Suzuki, K. (2015) Longitudinal Analyses of Childhood Growth: Evidence from Project Koshu. Journal of Epidemiology, 25, 2-7. http://dx.doi.org/10.2188/jea.je20140130

[17] WHO Multicentre Growth Reference Study Group (2006) WHO Child Growth Standards Based on Length/Height, Weight and Age. Acta Paediatrica, 450, 76-85.

[18] Rolland-Cachera, M.F., Deheeger, M., Maillot, M., et al. (2006) Early Adiposity Rebound: Causes and Consequences for Obesity in Children and Adults. International Journal of Obesity, 30, S11-S17. http://dx.doi.org/10.1038/sj.ijo.0803514

[19] Ong, K.K., Preece, M.A., Emmett, P.M., et al. (2002) Size at Birth and Early Childhood Growth in Relation to Maternal Smoking, Parity and Infant Breast-Feeding: Longitudinal Birth Cohort Study and Analysis. Pediatric Research, 52, 863-867. http://dx.doi.org/10.1203/00006450-200212000-00009

[20] Eriksson, J.G., Forsén, T., Tuomilehto, J., et al. (2003) Early Adiposity Rebound in Childhood and Risk of Type 2 Diabetes in Adult Life. Diabetologia, 46, 190-194. http://dx.doi.org/10.1007/s00125-002-1012-5

[21] Freedman, D.S., Kettel Khan, L., Serdula, M.K., et al. (2001) BMI Rebound, Childhood Height and Obesity among Adults: The Bogalusa Heart Study. International Journal of Obesity, 25, 543-549. http://dx.doi.org/10.1038/sj.ijo.0801581

[22] Robinson, S.M., Crozier, S.R., Harvey, N.C., et al. (2015) Modifiable Early-Life Risk Factors 
for Childhood Adiposity and Overweight: An Analysis of Their Combined Impact and Potential for Prevention. The American Journal of Clinical Nutrition, 101, 368-375.

http://dx.doi.org/10.3945/ajcn.114.094268

[23] Stout, S.A., Espel, E.V., Sandman, C.A., et al. (2015) Fetal Programming of Children's Obesity Risk. Psychoneuroendocrinology, 53, 29-39.

http://dx.doi.org/10.1016/j.psyneuen.2014.12.009

[24] Power, C. and Jefferis, B.J. (2002) Fetal Environment and Subsequent Obesity: A Study of Maternal Smoking. International Journal of Epidemiology, 31, 413-419.

http://dx.doi.org/10.1093/ije/31.2.413

[25] Toschke, A., Koletzko, B., Slikker Jr., W., et al. (2002) Childhood Obesity Is Associated with Maternal Smoking in Pregnancy. European Journal of Pediatrics, 161, 445-448. http://dx.doi.org/10.1007/s00431-002-0983-z

[26] Suzuki, K., Kondo, N., Sato, M., et al. (2012) Maternal Smoking during Pregnancy and Childhood Growth Trajectory: A Random Effects Regression Analysis. Journal of Epidemiology, 22, 175-178. http://dx.doi.org/10.2188/jea.JE20110033

[27] Zarrati, M., Shidfar, F., Moradof, M., et al. (2013) Relationship between Breast Feeding and Obesity in Children with Low Birth Weight. Iranian Red Crescent Medical Journal, 15, 676682. http://dx.doi.org/10.5812/ircmj.11120

[28] Bergmann, K.E., Bergmann, R.L., Von Kries, R., et al. (2003) Early Determinants of Childhood Overweight and Adiposity in a Birth Cohort Study: Role of Breast-Feeding. International Journal of Obesity and Related Metabolic Disorders, 27, 162-172.

http://dx.doi.org/10.1038/sj.ijo.802200 


\section{Supplemental}

Table S1. Regression coefficients describing the effects of BMI during infancy.

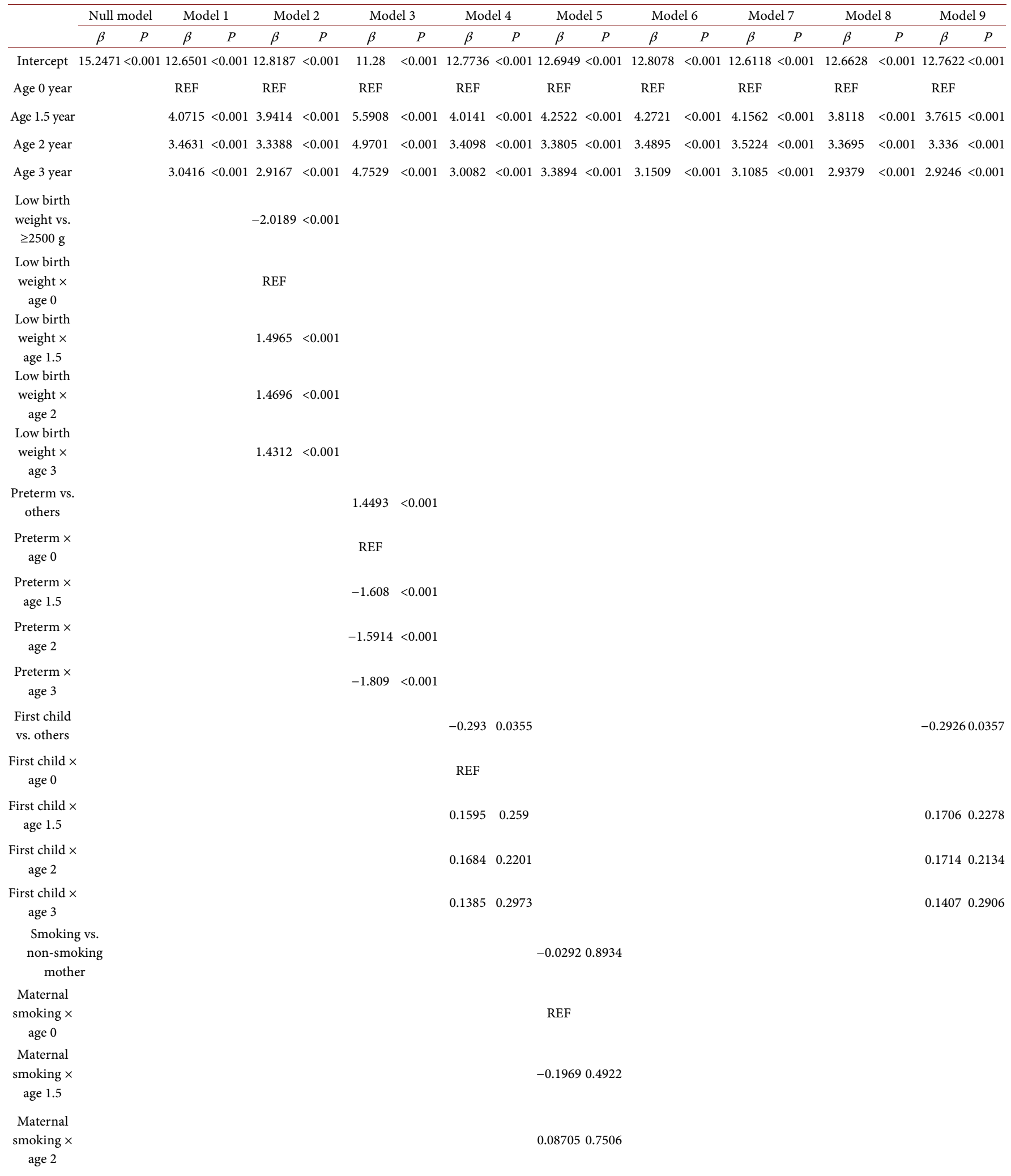




\section{Continued}

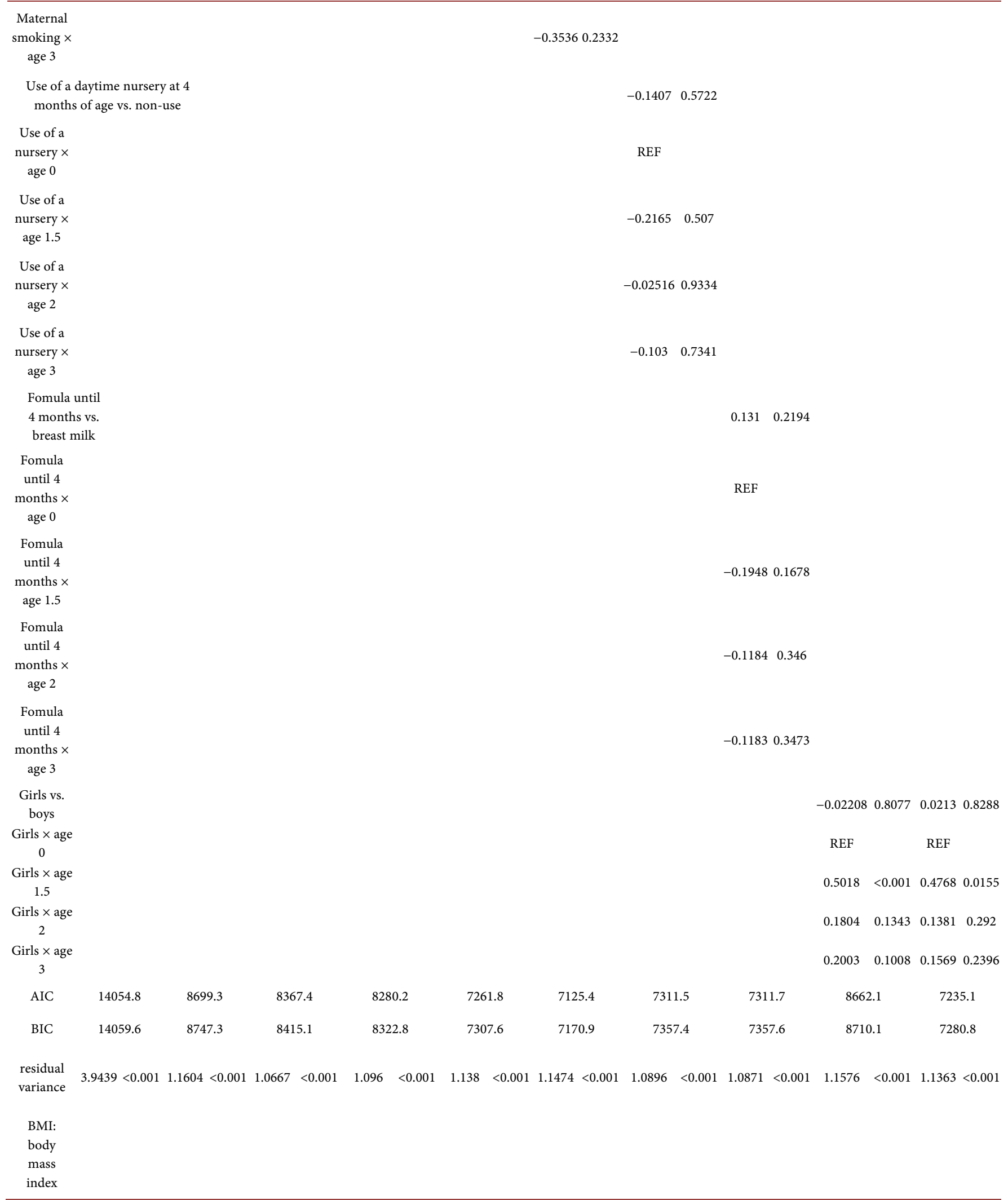


Submit or recommend next manuscript to SCIRP and we will provide best service for you:

Accepting pre-submission inquiries through Email, Facebook, LinkedIn, Twitter, etc. A wide selection of journals (inclusive of 9 subjects, more than 200 journals)

Providing 24-hour high-quality service

User-friendly online submission system

Fair and swift peer-review system

Efficient typesetting and proofreading procedure

Display of the result of downloads and visits, as well as the number of cited articles

Maximum dissemination of your research work

Submit your manuscript at: http://papersubmission.scirp.org/

Or contact health@scirp.org 